\title{
Superfast tellurizing synthesis of unconventional phase-controlled small Pd-Te nanoparticles
}

\author{
Yi Han ${ }^{1}$, Yanyun Zhang ${ }^{1}$, Xinyi Zhang ${ }^{1}$, Yuyao Sun ${ }^{1}$, Wenwen $\mathrm{Cai}^{1}$, Zhenjiang $\mathrm{Li}^{3}$, Jianping Lai ${ }^{{ }^{*}}$ and \\ Lei Wang ${ }^{1,2^{*}}$
}

\begin{abstract}
Large-scale production of unconventional phase-controlled telluride catalysts in a simple and fast manner still poses a great challenge. Herein, we develop a superfast tellurizing synthesis method that can quickly prepare unconventional phase-controlled palladium telluride nanoparticles (Pd-Te NPs) on carbon nanotubes (CNTs) (i.e., $\mathrm{PdTe} / \mathrm{CNT}, \mathrm{Pd}_{20} \mathrm{Te}_{7} / \mathrm{CNT}$ ) in $60 \mathrm{~s}$. By merely tuning the mass of the tellurium precursors under the same conditions, fine (about $5.5 \mathrm{~nm}$ ) and high-yield (about 90\%) hexagonal structured $\mathrm{PdTe} / \mathrm{CNT}$ and rhombohedral structured $\mathrm{Pd}_{20} \mathrm{Te}_{7} / \mathrm{CNT}$ can be precisely synthesized. The hexagonal structured PdTe/ CNT exhibits excellent performance for glycerol oxidation reaction (GOR) and ethylene glycol oxidation reaction (EGOR). Specifically, the highest current density for GOR is 2.72 $\mathrm{A} \mathrm{mg}_{\mathrm{Pd}^{-1}}{ }^{-1}$, which is 1.9 -fold higher than that of rhombohedral structured $\mathrm{Pd}_{20} \mathrm{Te}_{7} / \mathrm{CNT}$, and 2.8-fold higher than that of $\mathrm{Pd} / \mathrm{CNT}$. It also outperforms most catalysts reported in GOR. Meanwhile, the specific activity for EGOR is 3.65 $\mathrm{A} \mathrm{mg}_{\mathrm{Pd}^{-1}}{ }^{-1}$, which is 2.1 and 3.9 times higher than those of rhombohedral structured $\mathrm{Pd}_{20} \mathrm{Te}_{7} / \mathrm{CNT}$ and $\mathrm{Pd} / \mathrm{CNT}$. We hope that this work can provide guidance for the preparation of crystalline phase-controlled telluride catalysts via new tellurization and inspire the application of crystalline phasecontrolled materials.
\end{abstract}

Keywords: scalable production, phase-controlled catalysts, telluride, fuel cell

\section{INTRODUCTION}

Fuel cell (FC) is widely considered one of the most effective approaches to solve the environmental pollution and low power generation efficiency of fossil fuels [1-12]. Nowadays, alkaline polyols FCs are progressively gaining attention in the field of FC because polyhydric alcohols have shown unique advantages relative to methanol, such as lower toxicity, low volatility, low flammability, and high energy densities [13-19]. Unfortunately, the lack of active and stable electrocatalysts has severely impeded the large-scalable commercialization of alkaline polyols FCs [2026]. Palladium tellurides ( $\mathrm{Pd}-\mathrm{Te}$ ) have been proved to be an efficient catalyst for methanol electrooxidation and ethanol electrooxidation [27]. The existence of $\mathrm{Te}$ in metal-tellurides could enhance noble-metal utilization, modify the electronic structure of electrocatalysts, facilitate reaction kinetics, and enhance anti-CO poisoning ability, thus displaying high performance in alkaline FCs $[28,29]$.

However, to date, the alkaline polyols oxidation activity of Pd-Te NPs has not been explored, especially the phase-controlled ones [30-34]. Traditional synthesis methods of Pd-Te NPs (such as solvothermal method [29,31], and oil bath synthesis method [35]) and traditional phase-controlled synthesis methods (such as the electrochemical deposition, solvothermal synthesis, and high-temperature calcination [36-43]) are complicated, time-consuming, and require complicated equipment. Moreover, solvents are usually involved in these general methods, resulting in high-energy consumption and environmental pollution. Besides, due to the long-term high-temperature environment during the particle growth process, the metastable crystal phase transforms into a thermodynamically stable crystal phase, and small nanoparticles (NPs) agglomerate. To prevent the aggregation of particles, additives are usually used to form a protective layer, which can impede the catalytic activity of the catalyst [44-52]. Therefore, a more effective, simple, and rapid tellurizing method is required to synthesize crystalline phasecontrolled Pd-Te NPs.

In this study, we firstly develop a fast tellurizing method that can quickly prepare unconventional phase-controlled $\mathrm{Pd}-\mathrm{Te}$ $\mathrm{NPs}$ on carbon nanotubes (CNTs) (i.e., PdTe/CNT, $\mathrm{Pd}_{20} \mathrm{Te}_{7} /$ CNT) by solvent-free microwaving. The traditional tellurization method is process-complicated, time-consuming (usually more than $1 \mathrm{~h}$ ), surfactant-involved, and leads to the synthesis of tellurides with a size of larger than $50 \mathrm{~nm}$. However, in the proposed tellurizing method, only a household microwave oven is needed to synthesize the hexagonal structured PdTe/CNT and rhombohedral structured $\mathrm{Pd}_{20} \mathrm{Te}_{7} / \mathrm{CNT}$ (5.5 nm) in one step and $1 \mathrm{~min}[29,30,35,53]$. This process is simple, fast, and requires low equipment, which has great potential for industrial production. Furthermore, considering the green sustainable chemistry, the whole process is surfactant- and solvent-free, causing it to be more energy-efficient and beneficial than traditional

\footnotetext{
${ }^{1}$ Key Laboratory of Eco-Chemical Engineering, Key Laboratory of Optic-electric Sensing and Analytical Chemistry of Life Science, Taishan Scholar Advantage and Characteristic Discipline Team of Eco-Chemical Process and Technology, College of Chemistry and Molecular Engineering, Qingdao University of Science and Technology, Qingdao 266042, China

${ }^{2}$ Shandong Engineering Research Center for Marine Environment Corrosion and Safety Protection, College of Environment and Safety Engineering, Qingdao University of Science and Technology, Qingdao 266042, China

${ }^{3}$ College of Materials Science and Engineering, Qingdao University of Science and Technology, Qingdao 266042, China

*Corresponding authors (emails: jplai@qust.edu.cn (Lai J); inorchemwl@126.com (Wang L))
} 
methods. The hexagonal structured PdTe/CNT exhibits excellent performance for glycerol oxidation reaction (GOR) and ethylene glycol oxidation reaction (EGOR). Specifically, the specific activity for GOR is $2.72 \mathrm{~A} \mathrm{mg}_{\mathrm{Pd}}{ }^{-1}$, which is 1.9 -fold higher than that of rhombohedral structured $\mathrm{Pd}_{20} \mathrm{Te}_{7} / \mathrm{CNT}$ and 2.7-fold higher than that of Pd/CNT. Meanwhile, the specific activity for EGOR is $3.65 \mathrm{~A} \mathrm{mg}_{\mathrm{Pd}}{ }^{-1}$, which is 2.1 and 3.9 times higher than those of rhombohedral structured $\mathrm{Pd}_{20} \mathrm{Te}_{7} / \mathrm{CNT}$ and $\mathrm{Pd} / \mathrm{CNT}$.

\section{EXPERIMENTAL SECTION}

\section{Materials}

Palladium diacetylacetonate $\left(\mathrm{Pd}(\mathrm{acac})_{2}, 97 \%\right)$ and Nafion solution (5\%) were bought from Sigma-Aldrich (Shanghai) Trading Co., Ltd. China. Te powder (97\%), potassium hydroxide $(\mathrm{KOH}$, 90\%), and carboxylated multi-walled CNTs (MWCNTs) were purchased from Aladdin. The deionized water in the experiment was ultrapure water $(18.2 \mathrm{M} \Omega \mathrm{cm})$.

\section{Preparation of rhombohedral structured $\mathrm{Pd}_{20} \mathrm{Te}_{7} / \mathrm{CNT}$}

First, $10 \mathrm{mg}$ of palladium acetylacetonate $\left(\operatorname{Pd}(\mathrm{acac})_{2}\right), 1 \mathrm{mg}$ of $\mathrm{Te}$ powder, and $10 \mathrm{mg}$ of MWCNTs were put into a quartz mortar and ground for $30 \mathrm{~min}$. Then, the black mixture was put into a quartz bottle and microwaved for $1 \mathrm{~min}$ in a microwave oven under a $\mathrm{N}_{2}$ atmosphere. Finally, the product was washed with ethanol two times and dried under vacuum.

\section{Preparation of hexagonal structured PdTe/CNT}

First, $10 \mathrm{mg}$ of $\mathrm{Pd}(\mathrm{acac})_{2}, 2 \mathrm{mg}$ of Te powder, and $10 \mathrm{mg}$ of MWCNTs were ground for $30 \mathrm{~min}$ in a quartz mortar. Then, the black mixture obtained was microwaved for $1 \mathrm{~min}$ in a microwave oven under a $\mathrm{N}_{2}$ atmosphere. Finally, the product was washed with ethanol two times and dried under vacuum.

\section{Preparation of $\mathrm{Pd} / \mathrm{CNT}$}

First, $10 \mathrm{mg}$ of $\mathrm{Pd}(\mathrm{acac})_{2}$ and $10 \mathrm{mg}$ of MWCNTs were ground for $30 \mathrm{~min}$ in a quartz mortar. Then, the black mixture obtained was microwaved for $1 \mathrm{~min}$ in a microwave oven under a $\mathrm{N}_{2}$ atmosphere. Finally, the product was washed with ethanol two times and dried under vacuum.

\section{Materials characterizations}

The transmission electron microscopy (TEM) and high-resolution TEM (HRTEM) (FEI Tecnai-G2 F30 with an accelerating voltage of $300 \mathrm{kV}$ ) were used to investigate the morphology and structure of the synthesized catalysts. The powder X-ray diffraction (XRD) (X'Pert-PRO MPD diffractometer with $\mathrm{Cu}-\mathrm{Ka}$ radiation at $40 \mathrm{kV}$ and $40 \mathrm{~mA}$ ) was used to investigate the structure of catalysts. The XRD patterns were collected in the $2 \theta$ range from $20^{\circ}$ to $80^{\circ}$. The inductively coupled plasma atomic emission spectrometer (ICP-AES, Varian 710-ES) was conducted to determine the content of elements. The X-ray photoelectron spectroscopy (XPS) with an Axis Supra spectrometer (monochromatic Al-Ka source at $15 \mathrm{~mA}$ and $14 \mathrm{kV}$ ) was used to determine the chemical and oxidation states of elements.

\section{Electrochemical measurements}

The electrochemical measurements were conducted in a threeelectrode system with a CHI760 electrochemical workstation, which was bought from the Shanghai Chenhua Instrument
Corporation, China. A glassy carbon electrode (GCE), a graphite rod, and a saturated calomel electrode were used as the working electrode, counter electrode, and reference electrode, respectively. Different catalysts of $1 \mathrm{mg}$ were dispersed in $1 \mathrm{~mL}$ of the solvent $\left(v_{\text {ethanol }}: v_{\text {Nafion }}=9: 1\right)$, and the mixture was sonicated for about $40 \mathrm{~min}$ to obtain a homogeneous catalyst ink. Then, $10 \mu \mathrm{L}$ of the ink was dropped onto the GCE surface for further measurements. To investigate the stability of the catalyst structure, $40 \mu \mathrm{L}$ of the ink was dropped onto the carbon paper (CP) for stability measurements and subsequent XRD characterization. All the potentials were converted to the reversible hydrogen electrode (RHE) via the equation: $E_{\mathrm{RHE}}=E_{\mathrm{SCE}}+0.0596 \mathrm{pH}+$ 0.244 . The electrochemically active surface area (ECSA) of the samples was reckoned according to the following equation:

$\mathrm{ECSA}=Q_{\mathrm{PdO}} /\left(Q_{\mathrm{r}} \times m_{\mathrm{Pd}}\right)$,

where $Q_{\mathrm{PdO}}$ is the integral area over the PdO reduction peak, $Q_{\mathrm{r}}$ is $405 \mu \mathrm{C} \mathrm{cm}{ }^{-2}$, and $m_{\mathrm{Pd}}$ is the mass of the Pd element in catalysts.

\section{RESULTS AND DISCUSSION}

The unconventional phase-controlled Pd-Te NPs on CNTs were prepared by a superfast tellurizing method (Fig. S1). By grinding MWCNTs, $\mathrm{Pd}(\mathrm{acac})_{2}$, and Te powders at room temperature, $\mathrm{Pd}$ precursor and Te sources were dispersed on the surfaces of CNTs, resulting in the ultra-short reaction path. The microwave conductive characteristics of MWCNTs can quickly provide a high-temperature environment caused by microwave radiation, promoting the rapid reaction between Te and $\mathrm{Pd}$. Notably, rapid temperature changes and the ultra-short diffusion path could effectively facilitate the reaction, inhibit the agglomeration of particles during growth, and form fine particles. Moreover, by merely tuning the mass of the tellurium precursors under the same conditions, the small (about $5.5 \mathrm{~nm}$ ), high-yield (about 90\%) hexagonal structured $\mathrm{PdTe} / \mathrm{CNT}$, and rhombohedral structured $\mathrm{Pd}_{20} \mathrm{Te}_{7} / \mathrm{CNT}$ can be precisely synthesized at the gram level.

Rhombohedral structured $\mathrm{Pd}_{20} \mathrm{Te}_{7} / \mathrm{CNT}$ was successfully synthesized when $1 \mathrm{mg}$ of Te powder was used in the reaction. TEM images and particle size distribution images display that NPs with an average diameter of $5.5 \mathrm{~nm}$ were synthesized on CNTs (Figs S2 and S3). As shown in the XRD pattern (Fig. 1a), the NPs synthesized on CNTs are rhombohedral structured $\mathrm{Pd}_{20} \mathrm{Te}_{7}$ (JCPDS No. 01-089-2014). Moreover, the HRTEM images present the lattice fringe of $0.239 \mathrm{~nm}$, corresponding to the (140) facet of rhombohedral structured $\mathrm{Pd}_{20} \mathrm{Te}_{7}$, verifying the successful synthesis of rhombohedral structured $\mathrm{Pd}_{20} \mathrm{Te}_{7} / \mathrm{CNTs}$ (Fig. 1b, c). ICP-AES results demonstrate the mass percentages of $\mathrm{Pd}$ and $\mathrm{Te}$, as $19.8 \%$ and $10.3 \%$, respectively. Moreover, the energy dispersive X-ray spectroscopy (EDX) element mapping and EDX line-scanning profile confirm that Pd and Te elements with atomic percentages of 21 and 9 atom $\%$ were distributed uniformly over all particles. The results further indicate the rhombohedral structured $\mathrm{Pd}_{20} \mathrm{Te}_{7} / \mathrm{CNT}$ was successfully obtained by the solvent-free microwave method (Fig. 1d, Figs S4 and S5). Moreover, XPS spectrum was employed to identify the chemical and oxidation states of the obtained rhombohedral structured $\mathrm{Pd}_{20} \mathrm{Te}_{7} / \mathrm{CNT}$. Fig. S6a presents the $\mathrm{Pd} 3 \mathrm{~d}$ spectrum for $\mathrm{Pd}_{20} \mathrm{Te}_{7} / \mathrm{CNT}$. The binding energy (BE) values at 335.9 and $341.3 \mathrm{eV}$ are attributed to $\mathrm{Pd} 3 \mathrm{~d}_{5 / 2}$ and $\mathrm{Pd} 3 \mathrm{~d}_{3 / 2}$, respectively, corresponding to $\mathrm{Pd}(0)$ species. In addition, peaks at 336.7 and $342.1 \mathrm{eV}$ can be assigned to $\mathrm{Pd}^{2+}$ species. Fig. S6b displays the 

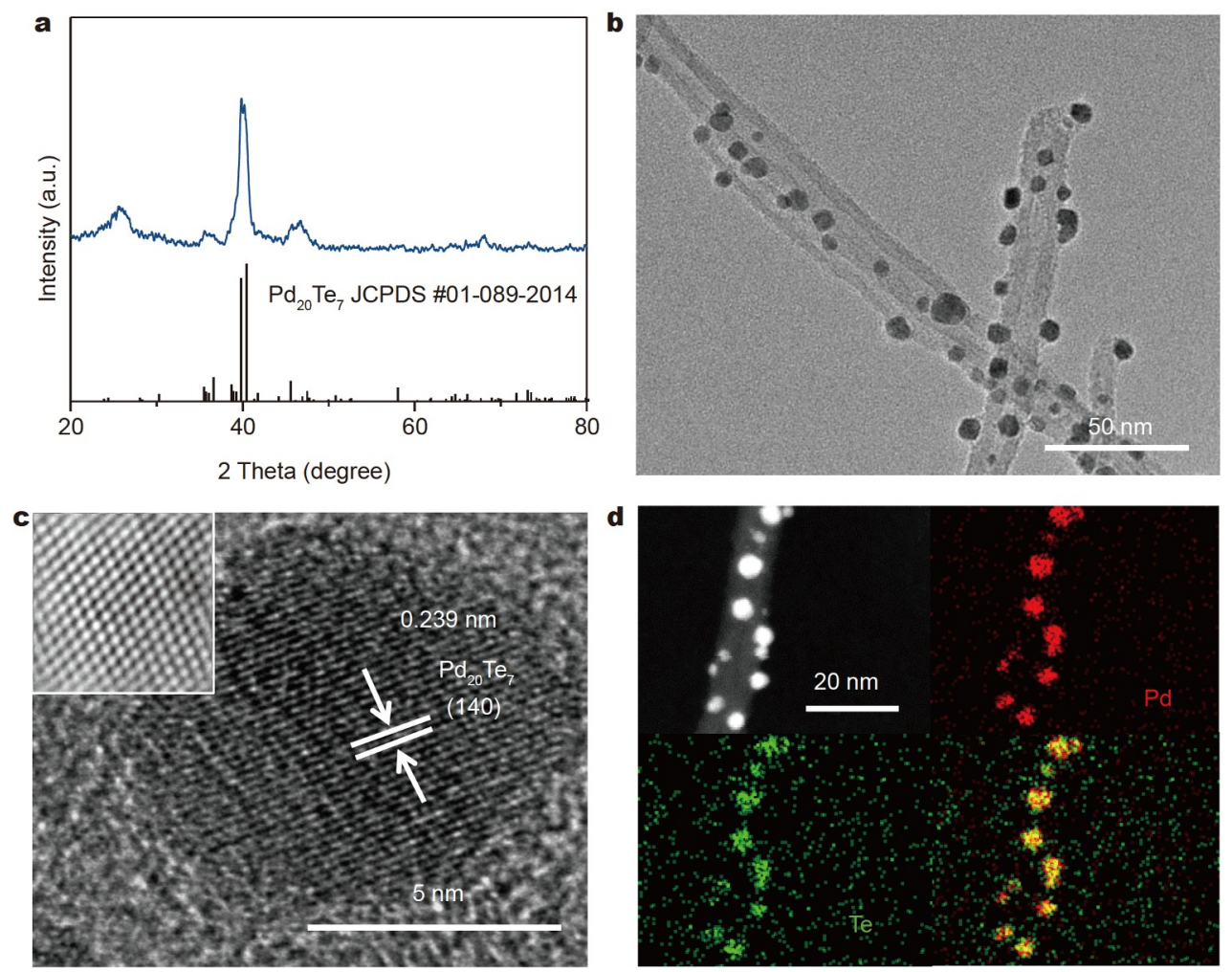

Figure 1 Morphology and characterization of rhombohedral structured $\mathrm{Pd}_{20} \mathrm{Te}_{7} / \mathrm{CNT}$. (a) XRD, (b) TEM, (c) HRTEM, and (d) EDX elemental mapping.

high-resolution Te $3 \mathrm{~d}$ XPS spectrum; the peaks at the BE values of 573.7 and $584.1 \mathrm{eV}$ are ascribed to $\mathrm{Te} 3 \mathrm{~d}_{5 / 2}$ and $\mathrm{Te} 3 \mathrm{~d}_{3 / 2}$, respectively. Two peaks at 576.3 and $586.6 \mathrm{eV}$ can be assigned to $\mathrm{Te}^{4+}$ species, which is in line with reported results, indicating the rhombohedral structured $\mathrm{Pd}_{20} \mathrm{Te}_{7} / \mathrm{CNT}$ were obtained.

By increasing the precursor mass of the tellurium to $2 \mathrm{mg}$, hexagonal structured PdTe/CNT was obtained. The XRD pattern reveals that the obtained NPs are isostructural to hexagonal structured PdTe (JCPDS No. 03-065-1901), indicating the successful synthesis of hexagonal structured PdTe (Fig. 2a). TEM images and particle size distribution images in Fig. $2 b$ and Fig. S7 indicate that PdTe NPs with an average diameter of $5.5 \mathrm{~nm}$ were well synthesized on CNTs. The HRTEM image reveals the lattice fringe spacing of about $0.303 \mathrm{~nm}$, corresponding to the (101) facet of hexagonal structured PdTe (Fig. 2c). ICP-AES results show the percentages of Pd and Te are respectively 10.2 and 9.1 atom\%. Moreover, EDX element mapping images and EDX line scan across hexagonal structured PdTe NPs show that Pd and Te elements with atomic percentages of 10.0 and 8.7 atom\% are distributed uniformly over all particles. This confirms that the hexagonal structured PdTe/ CNT NPs were successfully synthesized (Figs S2d, S8 and S9).

In addition, the chemical and oxidation states of the hexagonal structured PdTe/CNT were analyzed by XPS. Fig. S10a presents the $\mathrm{Pd} 3 \mathrm{~d}$ spectrum for PdTe/CNT. The BE values of 335.7 and $341.1 \mathrm{eV}$ are related to $\mathrm{Pd} 3 \mathrm{~d}_{5 / 2}$ and $\mathrm{Pd} 3 \mathrm{~d}_{3 / 2}$, respectively, corresponding to $\mathrm{Pd}(0)$ species. Peaks at 336.5 and $341.9 \mathrm{eV}$ can be assigned to $\mathrm{Pd}^{2+}$ species. Compared with hexagonal structured PdTe/CNT, a positive shift was observed for the Pd BE of the rhombohedral structured $\mathrm{Pd}_{20} \mathrm{Te}_{7} / \mathrm{CNT}$, indicating that a charge transfer process occurred between Pd and Te. According to the d-band theory, it also means that the center of the Pd d-band in the hexagonal structured PdTe/CNT is lower than that of the rhombohedral structured $\mathrm{Pd}_{20} \mathrm{Te}_{7} / \mathrm{CNT}$ [54]. Fig. S10b displays the high-resolution Te $3 \mathrm{~d}$ XPS spectrum, in which the peaks at the $\mathrm{BE}$ values of 573.9 and $584.3 \mathrm{eV}$ correspond to $\mathrm{Te} 3 \mathrm{~d}_{5 / 2}$ and Te $3 \mathrm{~d}_{3 / 2}$, respectively. Two peaks at 576.6 and $586.9 \mathrm{eV}$ can be assigned to $\mathrm{Te}^{4+}$ species, consistent with reported results, indicating that hexagonal structured PdTe/CNT was obtained. In addition, The $\mathrm{Pd} / \mathrm{CNT}$ s were synthesized without using a Te source during the synthesis process. As shown in the XRD pattern, TEM images, and particle size distribution images (Figs S11 and S12), the obtained Pd NPs with an average diameter of $5.3 \mathrm{~nm}$ were well synthesized on CNTs.

The electrochemical performance of $\mathrm{Pd}-\mathrm{Te} / \mathrm{CNT}$ with different crystalline phases was assessed in a traditional three-electrode setup. Fig. S13 shows the cyclic voltammetry (CV) curves and the corresponding ECSAs for both hexagonal structured $\mathrm{PdTe} / \mathrm{CNT}$, rhombohedral structured $\mathrm{Pd}_{20} \mathrm{Te}_{7} / \mathrm{CNT}$, and $\mathrm{Pd} /$ CNT in $\mathrm{N}_{2}$-saturated $1 \mathrm{~mol} \mathrm{~L}^{-1} \mathrm{KOH}$, as well as their Pd utilization efficiencies. As shown in Fig. S13a, the peaks around $0.7 \mathrm{~V}$ vs. RHE can be attributed to the reduction of $\mathrm{PdO}$ to $\mathrm{Pd}$, and the PdO peak of the hexagonal structured PdTe/CNT is positively shifted compared with other catalysts, which implies that new active sites exposed on the hexagonal structured PdTe/ CNT surface are easier to recover. According to the integrated area within the range of the PdO reduction peak, the ECSAs of samples can be calculated (Fig. S13b). Hexagonal structured PdTe/CNT shows a higher ECSA value $\left(43.6 \mathrm{~m}^{2} \mathrm{~g}_{\mathrm{Pd}}{ }^{-1}\right)$ than those of rhombohedral structured $\mathrm{Pd}_{20} \mathrm{Te}_{7} / \mathrm{CNT}\left(25.5 \mathrm{~m}^{2} \mathrm{~g}_{\mathrm{Pd}}{ }^{-1}\right)$ and $\mathrm{Pd} / \mathrm{CNT}\left(19.6 \mathrm{~m}^{2} \mathrm{~g}_{\mathrm{Pd}}{ }^{-1}\right)$. Moreover, the corresponding Pd utilization efficiencies of hexagonal structured PdTe/CNT, 

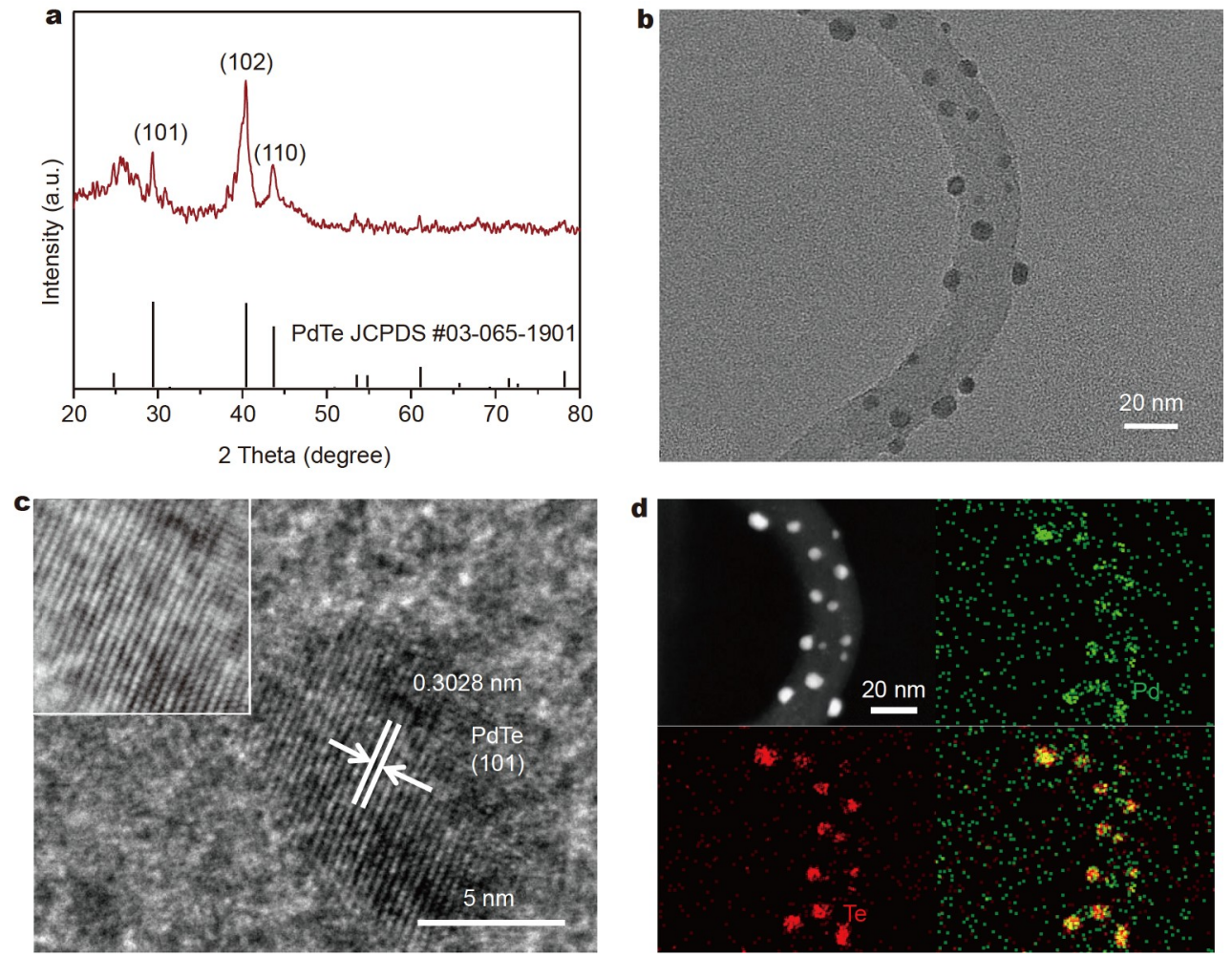

Figure 2 Morphology and characterization of hexagonal structured PdTe/CNT. (a) XRD, (b) TEM, (c) HRTEM, and (d) EDX elemental mapping.

rhombohedral structured $\mathrm{Pd}_{20} \mathrm{Te}_{7} / \mathrm{CNT}$, and $\mathrm{Pd} / \mathrm{CNT}$ are $9.7 \%$, $5.7 \%$, and $4.4 \%$, respectively (Fig. S13b) [55]. The GOR activities of $\mathrm{Pd}-\mathrm{Te} / \mathrm{CNT}$ with different phases were investigated by $\mathrm{CV}$ tests in $1 \mathrm{~mol} \mathrm{~L}^{-1} \mathrm{KOH}$ and $1 \mathrm{~mol} \mathrm{~L}^{-1}$ glycerol. Fig. 3a displays the $\mathrm{CV}$ curves of different catalysts in the GOR process. As shown in Fig. 3a, the higher peak $\left(I_{\mathrm{f}}\right)$ corresponds to the oxidation peak of glycerol, and the lower peak $\left(I_{\mathrm{b}}\right)$ corresponds to the oxidation peak of the intermediate product of glycerol oxidation. Hexagonal structured PdTe/CNT shows a higher $I_{\mathrm{f}}$ (2.72 $\mathrm{A} \mathrm{mg}_{\mathrm{Pd}}{ }^{-1}$ ) than rhombohedral structured $\mathrm{Pd}_{20} \mathrm{Te}_{7} / \mathrm{CNT}$ (1.42 $\mathrm{A} \mathrm{mg}_{\mathrm{Pd}^{-1}}{ }^{-1}$ ) and Pd/CNT (0.95 $\mathrm{A} \mathrm{mg}_{\mathrm{Pd}^{-1}}$ ), indicating that the PdTe/CNT has a superior GOR activity than others (Fig. 3a, b), outperforming most catalysts previously reported (Table S1). Moreover, $I_{\mathrm{f}} / I_{\mathrm{b}}$ is also an important factor in evaluating the tolerance of intermediate species to poisoning. The higher $I_{\mathrm{f}} / I_{\mathrm{b}}$ value of hexagonal structured PdTe/CNT (1.48) than that of rhombohedral structured $\mathrm{Pd}_{20} \mathrm{Te}_{7} / \mathrm{CNT}$ (1.43) and $\mathrm{Pd} / \mathrm{CNT}$ (1.29) indicates that the hexagonal structured PdTe/CNT has excellent GOR performance and intermediate anti-toxicity ability.

The stability of catalysts is also an essential factor in evaluating the electrocatalytic performance of $\mathrm{Pd}-\mathrm{Te} / \mathrm{CNT}$ with different phases. Fig. $3 c$ plots the long-term chronoamperometric current density-time $(i-t)$ curves for hexagonal structured PdTe/CNT, rhombohedral structured $\mathrm{Pd}_{20} \mathrm{Te}_{7} / \mathrm{CNT}$, and $\mathrm{Pd} / \mathrm{CNT}$. As shown in Fig. 3c, PdTe/CNT has a higher initial current density compared with $\mathrm{Pd} / \mathrm{CNT}$, implying that there are more active sites on the catalyst surface, which is consistent with the former results. The current decay observed in $i$ - $t$ curves of all samples can be attributed to the accumulation of toxic intermediates. Notably, the current density of the hexagonal structured PdTe/CNT is higher and decays more slowly than rhombohedral structured
$\mathrm{Pd}_{20} \mathrm{Te}_{7} / \mathrm{CNT}$ and $\mathrm{Pd} / \mathrm{CNT}$. The current density remained well after $1000 \mathrm{CV}$ cycles (Fig. 3d), and the structure, morphology, and chemical states of hexagonal structured PdTe/CNT could be retained almost unchanged (Figs S14-S18), further verifying that the hexagonal structured PdTe/CNT exhibits superior stability.

In addition, the EGOR performances of $\mathrm{Pd}-\mathrm{Te} / \mathrm{CNT}$ with different crystalline phases were also evaluated in $1 \mathrm{~mol} \mathrm{~L}^{-1}$ $\mathrm{KOH}$ and $1 \mathrm{~mol} \mathrm{~L}^{-1}$ ethylene glycol. As shown in Fig. 4a, b, hexagonal structured $\mathrm{PdTe} / \mathrm{CNT}$ has a current density of $3.65 \mathrm{~A} \mathrm{mg}_{\mathrm{Pd}}{ }^{-1}$, higher than that of rhombohedral structured $\mathrm{Pd}_{20} \mathrm{Te}_{7} / \mathrm{CNT}$ (1.71 $\mathrm{A} \mathrm{mg}_{\text {Pd }}{ }^{-1}$ ) and Pd/CNT (0.92 $\left.\mathrm{A} \mathrm{mg}_{\text {Pd }}{ }^{-1}\right)$. Meanwhile, the current density maintained well after $5000 \mathrm{~s} i$ - $t$ test and $1000 \mathrm{CV}$ cycles, demonstrating that hexagonal structured PdTe/CNT exhibits remarkable EGOR performance (Fig. 4c, d).

By further increasing the amount of Te powder to $4 \mathrm{mg}$ in the synthesis process, we obtained the catalyst PdTe-4/CNT. Compared with the XRD pattern of hexagonal structured PdTe/CNT, there is no obvious changes in the structure of PdTe-4/CNT but the diffraction intensity. The intensity increase demonstrates that the crystallinity and content of the $\mathrm{Pd}$-Te have also increased (Fig. S19). Meanwhile, as shown in Fig. S20, it is apparent that the size of PdTe-4 NPs is much bigger than PdTe NPs. It is considered that the excessive tellurization reaction leads to the agglomeration of particles. The electrochemical performance of the PdTe-4/CNT for GOR and EGOR has also been investigated and given in Fig. S21. As shown in Fig. S21a, b, with an increased amount of Te powder, the PdTe-4/CNT shows a lower ECSA value $\left(24.6 \mathrm{~m}^{2} \mathrm{~g}_{\mathrm{Pd}}{ }^{-1}\right)$ and lower $\mathrm{Pd}$ utilization efficiency than PdTe/CNT. As shown in Fig. S21c, d, PdTe-4/ CNT displays inferior EGOR and GOR performances than $\mathrm{PdTe} / \mathrm{CNT}\left(1.24,2.43 \mathrm{~A} \mathrm{mg}_{\mathrm{Pd}^{-1}}\right.$, respectively), which can be 

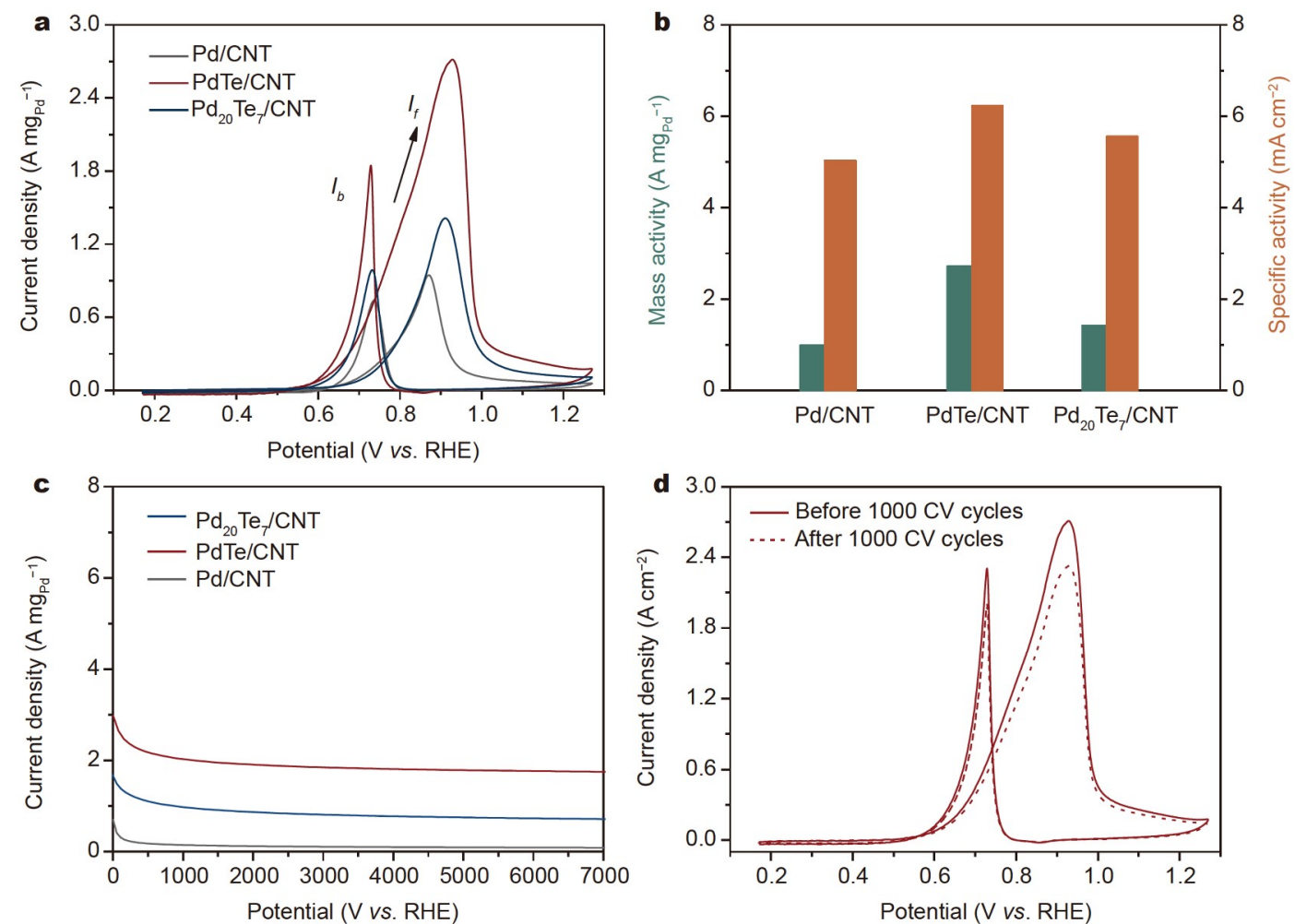

Figure 3 Glycerol electrooxidation performance of different electrocatalysts in $1 \mathrm{~mol} \mathrm{~L}^{-1} \mathrm{KOH}+1 \mathrm{~mol} \mathrm{~L}{ }^{-1}$ glycerol solution. (a) CVs, (b) corresponding histogram of mass activities, (c) chronoamperometric tests for GOR at $0.9 \mathrm{~V} v s$. RHE, and (d) CVs of hexagonal structured PdTe/CNT before and after 1000 CV cycles.
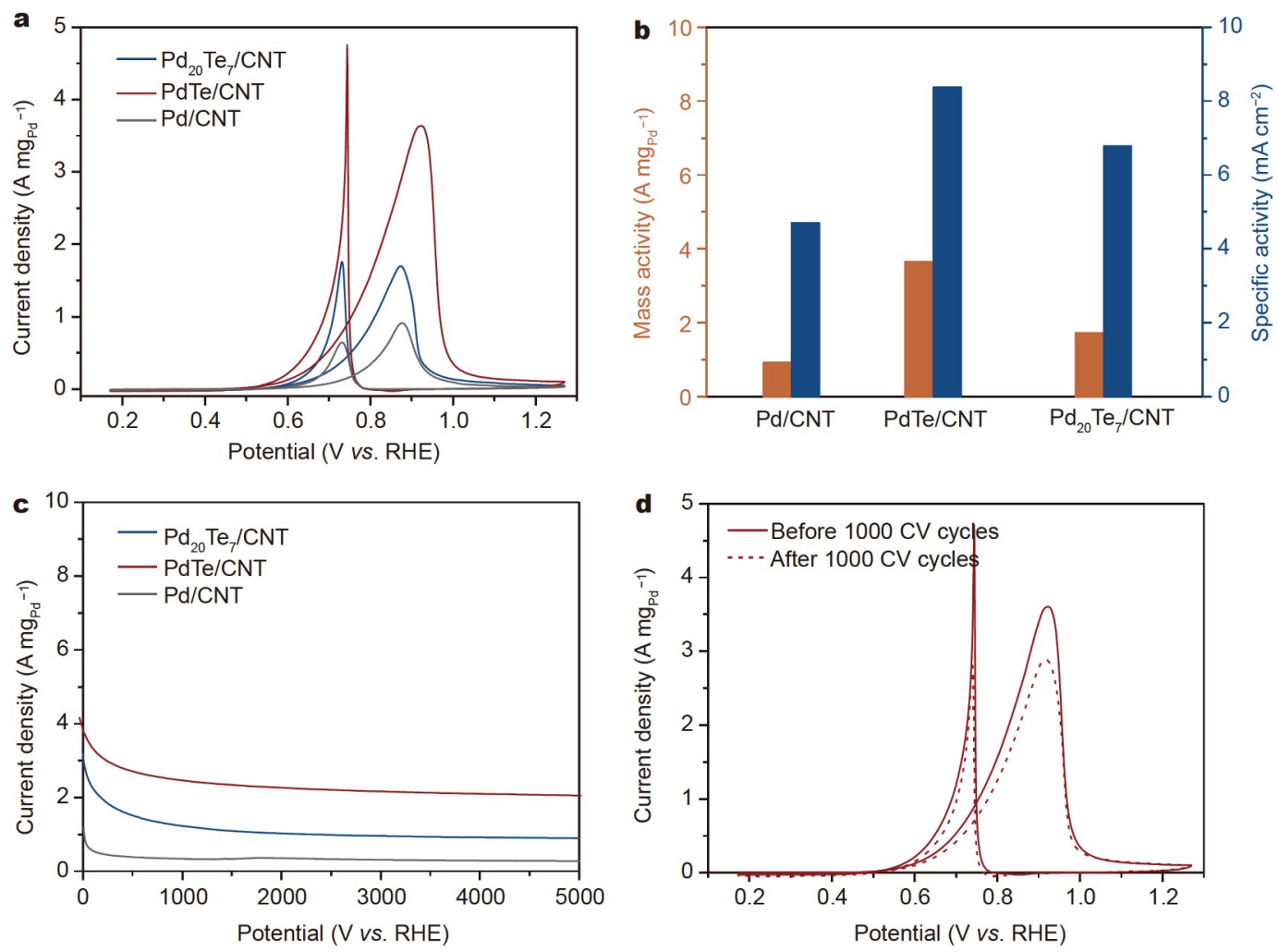

Figure 4 Ethylene glycol electrooxidation performance of different electrocatalysts in $1 \mathrm{~mol} \mathrm{~L}^{-1} \mathrm{KOH}+1 \mathrm{~mol} \mathrm{~L}{ }^{-1}$ ethylene glycol solution. (a) CVs, (b) corresponding histogram of mass activities, (c) chronoamperometric tests for EGOR at $0.9 \mathrm{~V} v s$. RHE, and (d) CVs of hexagonal structured PdTe/CNT before and after $1000 \mathrm{CV}$ cycles. 
attributed to the growth of PdTe NPs. Such growth of particles could decrease the number of active sites and weaken the contact area of the active phase and electrolyte, resulting in the decline of GOR and EGOR performances.

To explore the reason why the crystalline phase-controlled PdTe have stronger GOR activity, the electronic structure of the catalysts was analyzed by XPS. As shown in Fig. S22, the Pd $3 d_{5 / 2}$ and $\mathrm{Pd} 3 \mathrm{~d}_{3 / 2}$ peaks of hexagonal structured PdTe/CNT have shifted to the lower $\mathrm{BE}$ values, relative to the peaks of rhombohedral structured $\mathrm{Pd}_{20} \mathrm{Te}_{7} / \mathrm{CNT}$. This indicates a strong electronic interaction between $\mathrm{Pd}$ and $\mathrm{Te}$ which can be attributed to the lower electronegativity of Pd atoms. Accordingly, neighboring Te atoms could transfer part of the electrons to Pd atoms. Therefore, the Pd surface in hexagonal structured PdTe/CNT presents a higher electron content than that in rhombohedral structured $\mathrm{Pd}_{20} \mathrm{Te}_{7} / \mathrm{CNT}$. According to the d-band center theory, the $\mathrm{d}$ band of $\mathrm{Pd}$ moves downward, effectively reducing the adsorption of CO-like species, promoting its oxidizing ability to glycerin, and increasing its stability. Moreover, CO stripping experiments further verify the great poisoning resistance of hexagonal structured PdTe/CNT. As shown in Fig. 5, the electrooxidation peaks of $\mathrm{CO}$ adsorbed on $\mathrm{Pd} / \mathrm{CNT}$ are in the range of 0.69 to $0.95 \mathrm{~V}$, while the electrooxidation peaks of hexagonal structured $\mathrm{PdTe} / \mathrm{CNT}$ and rhombohedral structured $\mathrm{Pd}_{20} \mathrm{Te}_{7} /$ CNT are in the range of 0.63 to 1.08 and 0.67 to $1.07 \mathrm{~V}$, respectively. Compared with the oxidation peaks of $\mathrm{Pd} / \mathrm{CNT}$ and rhombohedral structured $\mathrm{Pd}_{20} \mathrm{Te}_{7} / \mathrm{CNT}$, the $\mathrm{CO}$ oxidation peak of hexagonal structured $\mathrm{PdTe} / \mathrm{CNT}$ is in a relatively negative voltage range, which proves that $\mathrm{Pd}$ on hexagonal structured $\mathrm{PdTe} / \mathrm{CNT}$ has a poor affinity for the $\mathrm{CO}$ adsorption and can effectively resist the $\mathrm{CO}$ poisoning. Such remarkable anti-toxicity ability enables the hexagonal structured PdTe/CNT with good catalytic activity and high stability in the GOR process.

Finally, to verify whether the synthesized Pd-Te/CNT can be produced in grams, we expanded the raw material by 300 times. As shown in Fig. S23, $2.7139 \mathrm{~g}$ of rhombohedral structured $\mathrm{Pd}_{20} \mathrm{Te}_{7} / \mathrm{CNT}$ and $2.7450 \mathrm{~g}$ of hexagonal structured PdTe/CNT were obtained, and the yield ratio reached $90.4 \%$ and $91.5 \%$, respectively. Such high yield further proves that the tellurizing method is fast, efficient, and can realize scalable production at lower costs.

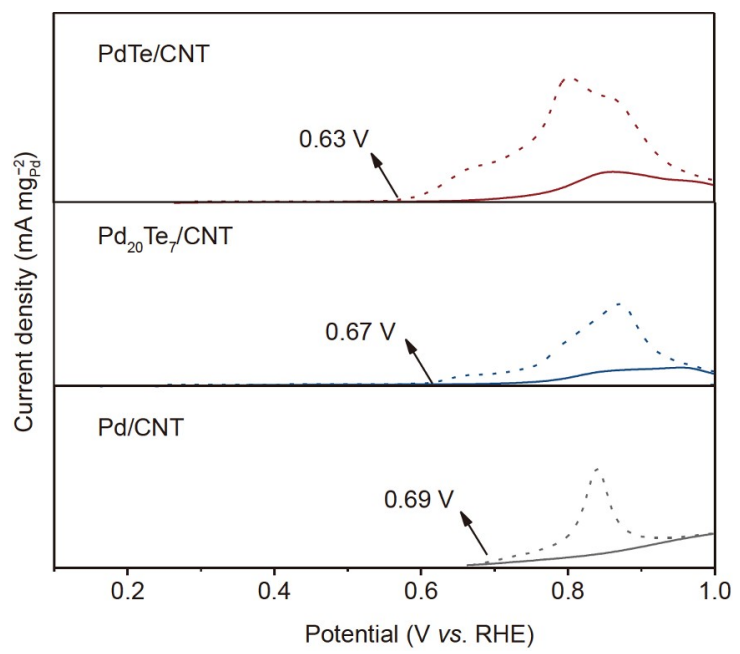

Figure 5 CO stripping curves of hexagonal structured $\mathrm{PdTe} / \mathrm{CNT}$, rhombohedral structured $\mathrm{Pd}_{20} \mathrm{Te}_{7} / \mathrm{CNT}$, and $\mathrm{Pd} / \mathrm{CNT}$ catalysts.

\section{CONCLUSIONS}

In conclusion, we have successfully developed a fast tellurizing method that can quickly prepare unconventional phase-controlled Pd-Te NPs on CNTs (i.e., PdTe/CNT, $\mathrm{Pd}_{20} \mathrm{Te}_{7} / \mathrm{CNT}$ ). Such tellurizing synthesis method only needs a household microwave oven, and the whole process is very fast $(60 \mathrm{~s})$, simple, surfactant-free, and scalable. By merely tuning the mass of the tellurium precursors under the same conditions, fine (about $5.5 \mathrm{~nm}$ ) and high-yield (about 90\%) hexagonal structured $\mathrm{PdTe} / \mathrm{CNT}$ and rhombohedral structured $\mathrm{Pd}_{20} \mathrm{Te}_{7} / \mathrm{CNT}$ can be precisely synthesized. The hexagonal structured PdTe/CNT displays a remarkable performance for both GOR and EGOR, which could be attributed to the strong chemical coupling effect between PdTe NPs and CNTs, the small size of PdTe NPs, and the strong electronic interactions between $\mathrm{Pd}$ and Te. Specifically, the specific activity for GOR was $2.72 \mathrm{~A} \mathrm{mg}_{\mathrm{Pd}}{ }^{-1}$, which is 1.9-fold higher than that of rhombohedral structured $\mathrm{Pd}_{20} \mathrm{Te}_{7} /$ CNT and 2.7-fold higher than that of Pd/CNT. Meanwhile, the specific activity for EGOR is $3.65 \mathrm{~A} \mathrm{mg}_{\mathrm{Pd}}{ }^{-1}$, which is 2.1 and 3.9 times higher than those of rhombohedral structured $\mathrm{Pd}_{20} \mathrm{Te}_{7} /$ $\mathrm{CNT}$ and Pd/CNT. Our work provides new guidance for the scalable preparation of crystalline phase-controlled catalysts via tellurization and can have a valuable contribution to the application of crystalline phase-controlled materials.

Received 24 October 2021; accepted 28 December 2021; published online 22 February 2022

1 Pedireddy S, Lee HK, Tjiu WW, et al. One-step synthesis of zerodimensional hollow nanoporous gold nanoparticles with enhanced methanol electrooxidation performance. Nat Commun, 2014, 5: 4947

2 Tian N, Zhou ZY, Sun SG, et al. Synthesis of tetrahexahedral platinum nanocrystals with high-index facets and high electro-oxidation activity. Science, 2007, 316: 732-735

3 Li C, Yuan Q, Ni B, et al. Dendritic defect-rich palladium-copper-cobalt nanoalloys as robust multifunctional non-platinum electrocatalysts for fuel cells. Nat Commun, 2018, 9: 3702

4 Huang H, Yang S, Vajtai R, et al. Pt-decorated 3D architectures built from graphene and graphitic carbon nitride nanosheets as efficient methanol oxidation catalysts. Adv Mater, 2014, 26: 5160-5165

$5 \mathrm{Xu} \mathrm{C}$, Wang $\mathrm{H}$, Shen $\mathrm{P}$, et al. Highly ordered Pd nanowire arrays as effective electrocatalysts for ethanol oxidation in direct alcohol fuel cells. Adv Mater, 2007, 19: 4256-4259

6 Gao F, Zhang Y, Song P, et al. Precursor-mediated size tuning of monodisperse PtRh nanocubes as efficient electrocatalysts for ethylene glycol oxidation. J Mater Chem A, 2019, 7: 7891-7896

7 Jin $\mathrm{H}, \mathrm{Li}$ L, Liu X, et al. Nitrogen vacancies on $2 \mathrm{D}$ layered $\mathrm{W}_{2} \mathrm{~N}_{3}$ : A stable and efficient active site for nitrogen reduction reaction. Adv Mater, 2019, 31: 1902709

8 Chen $\mathrm{L}, \mathrm{Lu} \mathrm{L}$, Zhu $\mathrm{H}$, et al. Improved ethanol electrooxidation performance by shortening Pd-Ni active site distance in Pd-N-P nanocatalysts. Nat Commun, 2017, 8: 14136

9 Li H, Han Y, Zhao H, et al. Fast site-to-site electron transfer of highentropy alloy nanocatalyst driving redox electrocatalysis. Nat Commun, 2020, 11: 5437

10 Lu Y, Wang W, Chen X, et al. Composition optimized trimetallic $\mathrm{PtNiRu}$ dendritic nanostructures as versatile and active electrocatalysts for alcohol oxidation. Nano Res, 2019, 12: 651-657

11 Geng SK, Zheng Y, Li SQ, et al. Nickel ferrocyanide as a high-performance urea oxidation electrocatalyst. Nat Energy, 2021, 6: 904-912

12 Kim HJ, Ahn YD, Kim J, et al. Surface elemental distribution effect of $\mathrm{Pt}-\mathrm{Pb}$ hexagonal nanoplates for electrocatalytic methanol oxidation reaction. Chin J Catal, 2020, 41: 813-819

13 Yang F, Ye JY, Yuan Q, et al. Ultrasmall Pd-Cu-Pt trimetallic twin icosahedrons boost the electrocatalytic performance of glycerol oxidation at the operating temperature of fuel cells. Adv Funct Mater, 2020, 


\section{0: 1908235}

14 Ma J, Mao K, Low J, et al. Efficient photoelectrochemical conversion of methane into ethylene glycol by $\mathrm{WO}_{3}$ nanobar arrays. Angew Chem Int Ed, 2021, 60: 9357-9361

15 Chen Z, Liu C, Zhao X, et al. Promoted glycerol oxidation reaction in an interface-confined hierarchically structured catalyst. Adv Mater, 2019, 31: 1804763

16 Munoz F, Hua C, Kwong T, et al. Palladium-copper electrocatalyst for the promotion of the electrochemical oxidation of polyalcohol fuels in the alkaline direct alcohol fuel cell. Appl Catal B-Environ, 2015, 174175: 323-328

17 Li S, Tian ZQ, Liu Y, et al. Hierarchically skeletal multi-layered Pt-Ni nanocrystals for highly efficient oxygen reduction and methanol oxidation reactions. Chin J Catal, 2021, 42: 648-657

18 Mougenot M, Caillard A, Simoes $\mathrm{M}$, et al. $\mathrm{PdAu} / \mathrm{C}$ catalysts prepared by plasma sputtering for the electro-oxidation of glycerol. Appl Catal BEnviron, 2011, 107: 372-379

19 Hong W, Shang C, Wang J, et al. Bimetallic PdPt nanowire networks with enhanced electrocatalytic activity for ethylene glycol and glycerol oxidation. Energy Environ Sci, 2015, 8: 2910-2915

20 de Souza MBC, Vicente RA, Yukuhiro VY, et al. Bi-modified Pt electrodes toward glycerol electrooxidation in alkaline solution: Effects on activity and selectivity. ACS Catal, 2019, 9: 5104-5110

21 Yang X, Yao K, Ye JY, et al. Interface-rich three-dimensional Au-doped $\mathrm{PtBi}$ intermetallics as highly effective anode catalysts for application in alkaline ethylene glycol fuel cells. Adv Funct Mater, 2021, 31: 2103671

22 Du H, Wang K, Tsiakaras P, et al. Excavated and dendritic Pt-Co nanocubes as efficient ethylene glycol and glycerol oxidation electrocatalysts. Appl Catal B-Environ, 2019, 258: 117951

23 Li H, Pan Y, Zhang D, et al. Surface oxygen-mediated ultrathin PtRuM $(\mathrm{Ni}, \mathrm{Fe}$, and $\mathrm{Co})$ nanowires boosting methanol oxidation reaction. J Mater Chem A, 2020, 8: 2323-2330

24 Ma XY, Chen Y, Wang H, et al. Electrocatalytic oxidation of ethanol and ethylene glycol on cubic, octahedral and rhombic dodecahedral palladium nanocrystals. Chem Commun, 2018, 54: 2562-2565

25 Li S, Lai J, Luque R, et al. Designed multimetallic Pd nanosponges with enhanced electrocatalytic activity for ethylene glycol and glycerol oxidation. Energy Environ Sci, 2016, 9: 3097-3102

26 Qiao B, Yang $\mathrm{T}$, Shi $\mathrm{S}$, et al. Highly active hollow $\mathrm{RhCu}$ nanoboxes toward ethylene glycol electrooxidation. Small, 2021, 17: 2006534

27 Jin $\mathrm{L}, \mathrm{Xu} \mathrm{H}$, Chen $\mathrm{C}$, et al. Superior ethanol oxidation electrocatalysis enabled by ternary Pd-Rh-Te nanotubes. Inorg Chem, 2019, 58: 1237712384

28 Qiao W, Yang X, Li M, et al. Hollow $\mathrm{Pd} / \mathrm{Te}$ nanorods for the effective electrooxidation of methanol. Nanoscale, 2021, 13: 6884-6889

29 He Y, Yan D, Wang S, et al. Topological type-II Dirac semimetal and superconductor $\mathrm{PdTe}_{2}$ for ethanol electrooxidation. Energy Technol, 2019, 7: 1900663

30 Yuan M, Li Q, Zhang J, et al. Engineering surface atomic architecture of $\mathrm{NiTe}$ nanocrystals toward efficient electrochemical $\mathrm{N}_{2}$ fixation. Adv Funct Mater, 2020, 30: 2004208

31 Li HH, Zhao S, Gong M, et al. Ultrathin PtPdTe nanowires as superior catalysts for methanol electrooxidation. Angew Chem Int Ed, 2013, 52: $7472-7476$

32 Wang H, Yin S, Li C, et al. Direct synthesis of superlong Pt|Te mesoporous nanotubes for electrocatalytic oxygen reduction. J Mater Chem A, 2019, 7: 1711-1717

33 Wang J, Han L, Huang B, et al. Amorphization activated rutheniumtellurium nanorods for efficient water splitting. Nat Commun, 2019, 10: 5692

34 Zhao F, Zheng L, Yuan Q, et al. Ultrathin PdAuBiTe nanosheets as high-performance oxygen reduction catalysts for a direct methanol fuel cell device. Adv Mater, 2021, 33: 2103383

35 Arora A, Oswal P, Rao GK, et al. Catalytically active nanosized $\mathrm{Pd}_{9} \mathrm{Te}_{4}$ (telluropalladinite) and PdTe (kotulskite) alloys: First precursor-architecture controlled synthesis using palladium complexes of organotellurium compounds as single source precursors. RSC Adv, 2021, 11: $7214-7224$

36 Fan Z, Zhang H. Crystal phase-controlled synthesis, properties and applications of noble metal nanomaterials. Chem Soc Rev, 2016, 45: 6382

37 Chen Q, Cheng T, Fu H, et al. Crystal phase regulation in noble metal nanocrystals. Chin J Catal, 2019, 40: 1035-1056

38 Yang Z, Zhao T, Huang X, et al. Modulating the phases of iron carbide nanoparticles: From a perspective of interfering with the carbon penetration of $\mathrm{Fe}_{\mathrm{N}} \mathrm{Fe}_{3} \mathrm{O}_{4}$ by selectively adsorbed halide ions. Chem Sci, 2017, 8: 473-481

39 Ding J, Bu L, Guo S, et al. Morphology and phase controlled construction of Pt-Ni nanostructures for efficient electrocatalysis. Nano Lett, 2016, 16: 2762-2767

40 Wang J, Zhang J, Liu G, et al. Crystal phase-controlled growth of $\mathrm{PtCu}$ and $\mathrm{PtCo}$ alloys on $4 \mathrm{H} \mathrm{Au}$ nanoribbons for electrocatalytic ethanol oxidation reaction. Nano Res, 2020, 13: 1970-1975

41 Ge Y, Huang Z, Ling C, et al. Phase-selective epitaxial growth of heterophase nanostructures on unconventional 2H-Pd nanoparticles. J Am Chem Soc, 2020, 142: 18971-18980

42 Tong W, Huang B, Wang $\mathrm{P}$, et al. Crystal-phase-engineered $\mathrm{PdCu}$ electrocatalyst for enhanced ammonia synthesis. Angew Chem Int Ed, 2020, 59: 2649-2653

43 Wang X, Zhuang L, Jia Y, et al. Plasma-triggered synergy of exfoliation, phase transformation, and surface engineering in cobalt diselenide for enhanced water oxidation. Angew Chem Int Ed, 2018, 57: 16421-16425

44 Ma Z, Yu J, Dai S. Preparation of inorganic materials using ionic liquids. Adv Mater, 2010, 22: 261-285

45 Liu L, Wu J, Wu L, et al. Phase-selective synthesis of $1 \mathrm{~T}^{\prime} \mathrm{MoS}_{2}$ monolayers and heterophase bilayers. Nat Mater, 2018, 17: 1108-1114

$46 \mathrm{Yu} \mathrm{Z,} \mathrm{Xu} \mathrm{S,} \mathrm{Feng} \mathrm{Y,} \mathrm{et} \mathrm{al.} \mathrm{Phase-controlled} \mathrm{synthesis} \mathrm{of} \mathrm{Pd-Se} \mathrm{nano-}$ crystals for phase-dependent oxygen reduction catalysis. Nano Lett, 2021, 21: 3805-3812

47 Han HS, Choi H, Mhin S, et al. Advantageous crystalline-amorphous phase boundary for enhanced electrochemical water oxidation. Energy Environ Sci, 2019, 12: 2443-2454

48 Wang J, Ji Y, Shao Q, et al. Phase and structure modulating of bimetallic $\mathrm{CuSn}$ nanowires boosts electrocatalytic conversion of $\mathrm{CO}_{2}$. Nano Energy, 2019, 59: 138-145

49 Piao JY, Gu L, Wei Z, et al. Phase control on surface for the stabilization of high energy cathode materials of lithium ion batteries. J Am Chem Soc, 2019, 141: 4900-4907

50 Li H, Wang X. Phase control in inorganic nanocrystals through finely tuned growth at an ultrathin scale. Acc Chem Res, 2019, 52: 780-790

51 Han $\mathrm{X}, \mathrm{Yu} \mathrm{C}$, Huang $\mathrm{H}$, et al. Phase controllable synthesis of $\mathrm{Ni}^{2+}$ postmodified CoP nanowire for enhanced oxygen evolution. Nano Energy, 2019, 62: 136-143

52 Huang $\mathrm{W}, \mathrm{Ma} \mathrm{XY}$, Wang $\mathrm{H}$, et al. Promoting effect of $\mathrm{Ni}(\mathrm{OH})_{2}$ on palladium nanocrystals leads to greatly improved operation durability for electrocatalytic ethanol oxidation in alkaline solution. Adv Mater, 2017, 29: 1703057

53 Li X, Fang Y, Wang J, et al. Ordered clustering of single atomic Te vacancies in atomically thin $\mathrm{PtTe}_{2}$ promotes hydrogen evolution catalysis. Nat Commun, 2021, 12: 2351

54 Cai J, Huang Y, Guo Y. PdTe $e_{x} / \mathrm{C}$ nanocatalysts with high catalytic activity for ethanol electro-oxidation in alkaline medium. Appl Catal BEnviron, 2014, 150-151: 230-237

55 Singh RN, Singh A, Anindita A. Electrocatalytic activity of binary and ternary composite films of Pd, MWCNT and Ni, Part II: Methanol electrooxidation in $1 \mathrm{M} \mathrm{KOH}$. Int J Hydrogen Energy, 2009, 34: 20522057

Acknowledgements This work was supported by the National Natural Science Foundation of China (51772162, 22001143, and 52072197), the Youth Innovation and Technology Foundation of Shandong Higher Education Institutions, China (2019KJC004), the Outstanding Youth Foundation of Shandong Province, China (ZR2019JQ14), Taishan Scholar Young Talent Program (tsqn201909114 and tsqn201909123), the Natural Science Foundation of Shandong Province (ZR2020YQ34), the Major Scientific and Technological Innovation Project (2019JZZY020405), and the Major Basic Research Program of Natural Science Foundation of Shandong Province 
(ZR2020ZD09).

Author contributions Han Y performed the experiments, analyzed the data and wrote the manuscript. Zhang $\mathrm{Y}$ and Zhang $\mathrm{X}$ performed partial experiments and offered helpful suggestions. Sun Y and Cai W analyzed the data and offered helpful suggestions. Li $\mathrm{Z}$ contributed to the software and sources. Lai J contributed to the analysis, supervision and editing. Wang L contributed to the supervision and editing. All authors contributed to the general discussion.

Conflict of interest The authors declare that they have no conflict of interest.

Supplementary information Supporting data are available in the online version of the paper.

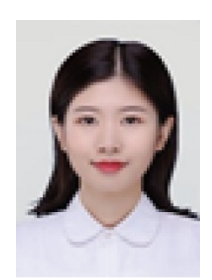

Yi Han is a PhD student at Qingdao University of Science and Technology. Her research mainly focuses on the design and synthesis of nanomaterials and their electrocatalytic applications.

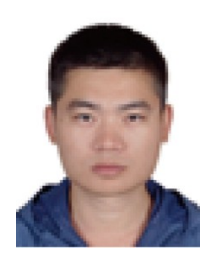

Jianping Lai received his $\mathrm{PhD}$ degree from Changchun Institute of Applied Chemistry, Chinese Academy of Sciences in 2017, and then he worked as a postdoctoral scholar at Peking University (2017-2019). In 2019, he joined Qingdao University of Science and Technology as a professor. His current research interests focus on clean energy electrocatalytic materials.

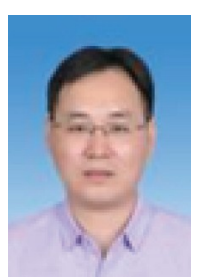

Lei Wang obtained his $\mathrm{PhD}$ degree in inorganic chemistry from Jilin University in 2006. He is now a professor in inorganic chemistry at the College of Chemistry and Molecular Engineering, Qingdao University of Science and Technology. The current research of his group focuses on the synthesis of nanosized functional materials for applications in photocatalysis, electrocatalysis, and batteries.

\section{一种超快的碲化法用于非常规相控碲化钯小纳米颗 粒的合成}

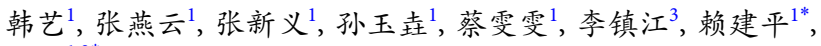
王否, , $^{*}$

摘要 本研究发展了一种超快的碲化方法, 可以在碳纳米管上快速制 备非常规相控磅化钯小纳米颗粒. 这种磅化方法只需要一台家用微波 炉, 整个过程非常快(60秒), 简单, 不含表面活性剂, 可规模化生产. 通 过在相同条件下仅调整前驱体 $\mathrm{Te}$ 粉的使用量, 可以精确调控合成小尺 寸(约 $5.5 \mathrm{~nm}$ )、高产率(约 $90 \%$ ) 的六方结构 $\mathrm{PdTe} / \mathrm{CNT}$ 和菱方结构 $\mathrm{Pd}_{20} \mathrm{Te}_{7} / \mathrm{CNT}$. 其中, 六方结构的 $\mathrm{PdTe} / \mathrm{CNT}$ 在甘油氧化反应 (GOR)和乙 二醇氧化反应 (EGOR)中表现出卓越的性能. 具体来说, 六方结构的 $\mathrm{PdTe} / \mathrm{CNT}$ 在甘油氧化反应中, 最高电流密度可达 $2.72 \mathrm{~A} \mathrm{mg}_{\mathrm{Pd}}{ }^{-1}$, 比菱 方结构 $\mathrm{Pd}_{20} \mathrm{Te}_{7} / \mathrm{CNT}$ 的最高电流密度高1.9倍, 比 $\mathrm{Pd} / \mathrm{CNT}$ 最高电流密度 高2.8倍, 超过了目前文献中报道过的大多数催化剂. 同时, 六方结构的 $\mathrm{PdTe} / \mathrm{CNT}$ 在乙二醇氧化反应中比活性达到 $3.65 \mathrm{~A} \mathrm{mg}_{\mathrm{Pd}}{ }^{-1}$, 比菱方结构 的 $\mathrm{Pd}_{20} \mathrm{Te}_{7} / \mathrm{CNT}$ 和 $\mathrm{Pd} / \mathrm{CNT}$ 分别高 2.1 倍和 3.9 倍. 我们希望这项工作可以 为小尺寸非常规相控磅化物催化剂的制备提供新的碲化方法指导, 并 为相控材料的应用提供启发. 